\title{
SELF-EXPRESSION IN CHILDREN \\ AS THE PHENOMENON OF SELF-ADVERTISEMENT
}

\section{Partyko Neonila ${ }^{1}$ \\ Savka Iryna ${ }^{2}$}

DOI: dx.doi.org/10.30525/978-9934-571-30-5_11

\begin{abstract}
The purpose of this paper is to carry out an investigation of the theoretical aspects of children's self-advertisement and to watch the level of self-expression they have. The methodological basis for the study was the psychological principles and provisions on a systematic approach to understanding the personality, on the activity approach to the development of the individual. A set of methods was used, namely: analysis, comparison, generalization of the scientific literature on children's self-expression, their socialization and self-promotion. Also, methods of observation and conversation revealed signs of self-promotion of children in their self-expression in the process of socialization. The problem of self-expression in children is closely related to the phenomenon of self-advertisement in adults. Many psychologists and philosophers studying the individual development of the child, deduce mental activity beyond the limits of social regulation, consider thinking within the framework of "subject-object" relations. Thus, the idea that social regulation is a secondary factor is pursued. Others, on the contrary, talk about thinking as a dialogue, about its inherently social nature. At present, this problem becomes particularly important in connection with the study of children's myth-making. According to Professor A. M. Lobok (1998) the child's thinking is "illogical" and "ispatially". Things and toys are animated, that is, they have a face - and this does not cause the child to be surprised. In the preschool child's game there is no time and space in the traditional adult view. Time can freely stretch and contract, and events during the game can occur with a complete violation of the laws of formal
\end{abstract}

\footnotetext{
${ }^{1}$ Candidate of Psychological Sciences, Associate Professor,

Associate Professor at Department of Theoretical and Practical Psychology,

Lviv Polytechnic National University, Ukraine

${ }^{2}$ Candidate of Psychological Sciences,

Associate Professor at Department of Theoretical and Practical Psychology,

Lviv Polytechnic National University, Ukraine
} 
logic. In fact, in accordance with this conception, it is this "arbitrariness" of the child's psyche, "isolation" from the adult's psyche, which, according to A. M. Lobok, is the source of the development of the subsequent individuality of the child, its "I". However, with all the obviousness of children's creative expression, it is absolutely unevident to deny the orientation of their thinking on social environment, on social assessments. Our observation of three-year-old children showed that their self-expression helps to advertise themselves and thus attract the attention of meaningful adults to children's self-affirmation. Children's self-affirmation, in turn, helps to grow up children of an early age. Based on the results of our conversations with the parents of these three-year-old children, this phenomenon has been confirmed in children of an early age.

\section{Introduction}

The motivation for self-expression and self-promotion, according to several authors, is exacerbated in adolescence. But what is self-expression in children and how it is motivated? The study of children's myth-making gives the opportunity to Professor A. Lobok to believe that the basis of children's thinking is not socialization in the traditional sense, when the child learns the norms of thinking and behavior of the elders and it is precisely as a result, it becomes a personality, an individuality, and initially predetermined, children's mythmaking, when a child creates myths, as it were, "from within" for self-expression without any orientation to immediate evaluation from the outside. In the preschool child's game there is no time and space in the traditional adult view. Time can freely stretch and contract, and events during the game can occur with a complete violation of the laws of formal logic. It is this "arbitrariness" of the child's psyche, "isolation" from the adult's psyche, which, according to A. M. Lobok, is the source of the development of the subsequent individuality of the child, its "I". However, with all the obviousness of children's creative expression, it is absolutely unevident to deny the orientation of their thinking on social environment, on social assessments. In turn, the psychologists dealing with the problem of social deprivation note a significant difference in the nature of the thinking processes of children who are raised in full-fledged families and in orphanages. It is the last long time that proves to be "informationally omnivorous". Those who are brought up in families who pay serious attention to this upbringing quickly acquire cultural skills and the forms of 


\section{Partyko Neonila, Savka Iryna}

organization of thinking, speech and behavior that are accepted in society. By creating a myth, a person, in particular a child, does not escape from reality, above all social. On the contrary, he declares about his existence, the desire to communicate, to be understood, to achieve respect, recognition. He wants to become closer, but at the same time to remain himself. However, from this contradictory state there is only one way out: socialization, correlation of individually constructed myth-words with public culture, gradual rejection of obscure myths, their transformation into understandable, for the sake of dialogue, for mutual understanding. The psychologists also note that in the process of communication between a child and adults, each of them develops in a logical way, and this happens in close connection with such psychological variables as self-esteem, achievement motivation, self-expression, "self image" and the like. Self-expression is a self-advertisement of a child becoming an adult, gradually from an unjustified desire to separate himself by any means and attract the attention of others gradually turns into a desire to justify the expectations of only significant people and to master only those cultural norms that are of value to him.

\section{Personality and self-advertisement}

From the point of view of the psychology of advertising, demonstrative behavior of people, their self-presentation is essentially no different from the activity of large organizations or firms that spend big money on advertising their names, goods and services. Firms by means of advertising tend to allocate their goods among similar ones, to present to the public its unique properties or to prove the conformity of this product to the best world samples. Likewise, some people communicate themselves, portray themselves in a more favorable light, exaggerate their dostoinstva and opportunities, try to stand out among equals, and at the same time seek to correspond to the level of those who are considered superior to themselves in terms of position in society.

Self-advertising is one of the most common and most ancient types of advertising activities. Just like traditional commercial advertising, it solves three problems. Engaged in self-advertisement, a person seeks: 1) to stand out among those people whom he values as equal to himself in the conditions of competition; 2) to present oneself as a person equal in status to those who have achieved any significant success and, possibly, even the legislator of a certain mode (social norms of behavior); 3 ) demonstrate yourself in the 
most favorable light, create a decent image, like others. In the first case, a person demonstrates unusual behavior; in the second - full correspondence to the established standards of behavior, norms, provided that they are significant for him; in the third - he tries to work on his own image, regardless of the presence of competition. In any case, the basis of human behavior is the same psychological mechanisms and, in fact, the same motivation. It is this multi-aspect of self-advertising that often reveals systemic contradictions in the study of this phenomenon. It should be noted that neither the theory of the "mirror I" by Ch. H. Cooley, nor the theory of "symbolic interactionism" of J. Meade, nor the theory of social instruction of A. Bandura, nor any other similar theories explain the sources of individuality of a person, the originality of his thinking and behavior, dissimilarity to other people. All of them are based on the notion that a person reproduces, in one way or another, preconceived patterns of behavior and thinking that have already been formed before him.

It should be noted that the source of originality or mediocrity of a person is not strictly localized. Factors that belong to the society are found out, but there are also grounds to believe that the behavior can be caused by the person himself. In any case, the society has the ability to set both stereotyped, standard norms of behavior, and non-standard ones.

These norms are fixed in culture. As a rule, any culture contains both norms. However, in a number of cases, for example, in different historical periods or depending on socioeconomic, political and other factors in a particular culture, either conservative norms of thinking and behavior, or avant-garde, can prevail. In the first case, culture finds itself in a prolonged stagnation, in the second it develops at a rapid pace and is renewed at an incredible speed, opposing the tradition of a rapidly changing fashion. The culture of the East is based on traditions handed down from generation to generation and changing very slowly. Modern culture of the West is extremely dynamic, is based on a rapidly changing fashion, that is, these two cultures have different sociodynamics (A. Mole, 1973).

Practical social psychology has always emphasized that every normally developing, active, socially oriented person tries to demonstrate to his surroundings his individuality, to prove that he is an exceptional personality with a sense of dignity. Public recognition of their mediocrity, loss of individuality and dignity, low self-esteem of a person are the result of conscious calculation or symptoms of a certain mental deviation. 


\section{Partyko Neonila, Savka Iryna}

Nevertheless, due to the protective mechanisms detailed in the psychoanalysis, people are often ashamed to admit to others and to themselves, which often manifests its social activity from ambitious motives. Under the influence of historically developing social (moral and ethical) norms, he usually hides and publicly denies the very possibility of such motivation as the reasons for his actions.

The motivation for self-expression and self-promotion, according to several authors, is exacerbated in adolescence. Here the manifestation of such motivation is most obvious and often manifests itself in an open defiant form, for example, in the form of any social movements, microcultures (punks, rockers, rappers, ravers, etc.), trends of demonstrative behavior (tattoo, piercing, scarification, etc.). This is due to a number of factors. First of all, young, but gradually maturing people "solve" the psychological problem of raising their social status. They do not need to attract attention and publicly demonstrate their successes, originality, individuality and independence, as growing up and personal advancement involves overcoming the strongest factor - the psychological pressure of adults involuntarily degrading the dignity of young people and holding back their ambitions and initiative.

Adult people who have accumulated life experience, with subconscious anxiety, lose their conquered social positions, knowingly or unconsciously view young people as potential competitors. At the same time, they want young people to look like the older generation. In this case it is easier to compete in social achievements, to restrict young people who do not want to "stand in line for social success". Thus, self-promotion can be a source of contradictions and the subject of psychological conflicts not only between individuals, but also between large groups. It should be noted also a characteristic feature of the self-expression of most young people: a great dependence on leaders and an understanding of their individuality and uniqueness as strict adherence to intragroup norms, reproduction of stereotypes created by other people.

Adolescence, in addition, is associated with a sharp exacerbation of the factor of sexual desire, and this necessarily leads to the activation of motivation for self-expression (self-promotion), the desire to excel, attract the attention of the opposite sex, etc. Here self-expression (self-advertisement) is very common manifested in an overly aggressive form and does not always coincide with the "co-keeping". 
Gradually, as you grow older, most people acquire the ability to hide their ambition, the desire to please, to stand out. They learn to explain the causes of their actions to other people by other motives. At the same time, there is a real substitution of frankly ambitious motives for others - a sense of duty, responsibility, etc. This is manifested especially sharply after the creation of the family, the birth of children, the education and success in the field of the career.

It is necessary to distinguish the concepts of vanity and ambition in analyzing the natural desire of every socially active person to differ from other people, drawing attention to one's personality. The essence of these concepts has not yet been uncovered by means of psychology, it is believed that these are concepts of ethics. So, ambition in certain optimal volumes is necessary for every person who takes an active socially oriented position in life. In this case, the well-bred among well-bred people may outwardly be absolutely imperceptible. Outwardly such a person can look modest and even shy. Ambition is revealed only when the psychological analysis of its actions and successes. Vanity, on the contrary, uses bright, conspicuous external attributes, emphasizing a person's desire to hear pleasant words in his address, laudatory reviews. It manifests itself in demonstrating its superiority, high social status, and very often in this case unjustified exaggeration is used, and so on.

In fact, ambition and vanity are only different external manifestations of one and the same social motivation. Different people, trying to come into contact and gain authority, choose different forms of self-correction. Very often such a choice is determined by people's ideas about what the partners in communication expect from them and what can attract the attention of the latter, to arouse their interest and respect by singling out the subject of self-advertisement from among other people by the presence of highly evaluated psycho-social and other characteristics and properties.

\section{Historical perspective of self-advertisement}

If we analyze the works of such well-known authors as E.B. Tylor, B. Malinovskii, L. Levi-Bruhl, J. Frezer, G. Spencer, C. Levi-Strauss and others, we often find only unsystematized utterances about the role of self-advertisement in people's lives in the distant past. Apparently, the whole point is that the advertising activity in the form of self-promotion is never manifested in a refined, unobjectified form. Its peculiarity is nonspe- 


\section{Partyko Neonila, Savka Iryna}

cificity, tight ties and interlacing with myths, magic, art, crafts, creativity, work, etc.

And today we are faced with the fact that there are no specific goods or services that allow satisfying the ambitious needs of the person. These needs are met functionally specific, for example, household goods and services, but designed and sold in a certain way, for example, at specific, unreasonably inflated prices, in special expensive packaging, etc.

The transition of cultures from primitive states to more developed occurred in different regions of the planet in different ways. So, the important point is to change the attitude of people to the means of attracting attention when moving from the preparation of products "for themselves" to making products "for others", for exchange, for sale. Many facts testify to the possibility of identifying certain general patterns of such a transition, and most importantly - to trace the role of advertising communications in this process.

In the creation of a symbolic image of the ruler or the dynasty of rulers, huge material resources were invested, thousands of people who died in wars, senseless for their political or social and economic purposes, were being sacrificed and exercised only to demonstrate power, to establish domination, to exalt not only the physical but and psychological power, the name of the ruler.

Death for glory, ambition, vanity, the desire to make yourself a center of universal attention characterized the social essence of large groups of people, which was reflected in a huge number of literary and historical works, myths, legends. For example, the myth of Herostratus, which destroyed the Temple of Artemis (one of Seven Wonders of the Ancient World) for the sake of glory, illustrates not only the character of the motivation of the ancient heroes, but also the attitude of ordinary people to such "feats". Sometimes entire nations, such as the Hellenes, created and specially fixed such social norms of behavior in which vanity was realized in the form of a "senseless feat" or an appreciable act was viewed as an ordinary phenomenon. Human life has turned into an event that, by its psychological mechanisms, does not differ from advertising activity in the conditions of the modern market.

If in the extreme antiquity the artist did not allow himself to pay special attention to his person, later authorship and self-expression become the norm that elevates art to the level of the highest achievements of culture. 
I. S. Kon claims that in the Renaissance the position of the artist changes: he looks at the image "from the outside", from the point of view of the alleged spectator. Hence the "objectivity" of the Renaissance portrait, and the principle possibility of self-portrait, for the writing of which the artist must see himself from the outside, make himself an object of observation. The appearance of the self-portrait required not only material prerequisites (good mirrors, which appear in medieval Europe only in the 13th century, glass mirrors were already in Rome, but then disappeared), but also socal and psychological prerequisites.

To write his own image, according to I. S. Kon, the artist should have not just a developed self-consciousness, but a consciousness of the value of his personality, worthy of perpetuation. Many masters of the Renaissance (Ghirlandaio, Botticelli, Filippino Lippi, Perugino, Pinturicchio, Rafael, Leonardo da Vinci, Michelangelo, Memling, Durer and others) depicted themselves as characters in their paintings. But the image of the artist never occupied a central place in these paintings and did not differ from other characters.

Only in the second half of the XV century self-portraits appeared. The development of this genre, according to I. S. Kon, reflects the social emancipation of artists who affirm their dignity in self-portraits. For example, the artist Rembrandt left after himself the largest in the history of painting a series of self-portraits (about 100).

Self-advertising in our days. Self-advertising in our days differs from self-promotion of the past only in content, in form it remains the same phenomenon that hundreds of thousands years ago. Just today, some other things, actions, rituals, decorations, clothes, cosmetics, habits, deeds, lifestyle, etc., are valuable, fashionable, socially significant and socially desirable. Although, in fact, social and psychological relations between people, their motivation practically does not change.

In addition, if in ancient times people themselves manufactured what was the subject of their self-promotion, in the Middle Ages - talented highly crafted craftsmen did it, today objects of achievement, prestige, objects used for self-promotion are often created by a flow conveyor belt using complex industrial technologies, robots and microprocessor technology.

It should be added that in our time, in certain cases, forms of self-expression are used that were known to our ancestors, for example, tattoos, piercings, scarification, etc. And also for a long time gold, beautiful 


\section{Partyko Neonila, Savka Iryna}

women, brave deeds and victories at all kinds of competitions remain in fashion.

From the point of view of modern psychology, the same social motivation, orientation to social evaluations, the desire to be no worse or better than other people, ambition, vanity, and self-image are at the basis of all the human actions we consider as self-expression and self-promotion, as well as in antiquity. envy, which in sociopsychological science is usually called "social comparison". People like to be paid attention to, and therefore they are eager for this.

A. Lebedev-Lyubimov believes that all insane records, the essence of which is self-expression and self-promotion, are recorded in the Guinness Book of Records and other similar publications in order to leave for posterity examples of imitation so that mankind does not stop the way from simple and primitive and even stupid forms of achievements and self-expression to even more stupid and meaningless.

Some information on the materials of the Guinness Book of Records. In 1991, at Christie's auction, the highest price was paid for the Cartier watch, called the Egyptian Renaissance. The watch of 1927 was sold for 905,882 pounds sterling. In 1994, a collector of French antiquities and art, an Iranian by birth, Jankhangir Rayyahie for the carpet of the era of Louis XV paid a record auction for the amount of more than one million pounds sterling. A certain gun collector who wished to remain anonymous bought a one-shot revolver "Colt" of the 45th caliber for 242 thousand dollars. The "value" of this "Colt" was that it was released at number one. Also, an unknown buyer bought a mechanical chain saw for 34,848 dollars, which was used in surgery a hundred years ago. In 1816, an English admirer of the talent of Mr. Isaac Newton acquired the tooth of a scientist for 730 pounds sterling. His compatriot, a bookseller from Cirencester, purchased the hair of the late Vice-Admiral Nelson. For this purchase he paid 5,500 pounds sterling.

\section{Socialization and self-presentation of children}

Professor A. M. Lobok (1998) believes that the basis of children's thinking is not socialization in the traditional sense, when the child learns the norms of thinking and behavior of the elders and it is precisely as a result, it becomes a personality, an individuality, and initially predetermined, children's mythmaking, when a child creates myths, as it were, "from within" 
for self-expression without any orientation to immediate evaluation from the outside.

In his opinion, the child's thinking is "illogical" and "ispatially ". Things and toys are animated, that is, they have a face - and this does not cause the child to be surprised. In the preschool child's game there is no time and space in the traditional adult view. Time can freely stretch and contract, and events during the game can occur with a complete violation of the laws of formal logic.

In fact, in accordance with this conception, it is this "arbitrariness" of the child's psyche, "isolation" from the adult's psyche, which, according to A. M. Lobok, is the source of the development of the subsequent individuality of the child, its "I". However, with all the obviousness of children's creative expression, it is absolutely unevident to deny the orientation of their thinking on social environment, on social assessments.

A. M. Lobok defends the idea, the essence of which is that the child is originally from nature endowed with an amazing ability to process information without regard to its biological and social needs. He seems to have an amazing, disinterested ability to "cram" information into himself without any objective reason. At the same time, the author does not explain either the purpose (reason) of such a child's ability, nor the mechanisms of its emergence. For example, he does not associate this ability with the social essence of man, does not consider it as a condition for the acquisition of a child's social experience, etc.

The psychologists dealing with the problem of social deprivation note a significant difference in the nature of the thinking processes of children who are raised in full-fledged families and in orphanages. It is the last long time that proves to be "informationally omnivorous". Those who are brought up in families who pay serious attention to this upbringing quickly acquire cultural skills and the forms of organization of thinking, speech and behavior that are accepted in society.

Thus, G. Kreig notes that in infants who show a sharp decrease in growth rates due to maternal deprivation or dysfunction, a disturbance of emotional ties can be detected. Such babies are usually small and depleted [4]. They look sick and are unable to properly digest food [4]. Sometimes they start eating right after they are placed in the hospital; in other cases they refuse to eat, remain sluggish and detached, almost immobile. These children often avoid eye contact, settling down in one point, turning away, covering their face or eyes [4, p. 319]. 


\section{Partyko Neonila, Savka Iryna}

W. Dennis found that children brought up in special institutions lag far behind in mastering such basic skills as the ability to sit, stand and walk if they have not opportunity to practice these skills. With almost complete absence of stimulation from the outside, there is a delay not only in motor development, but also in the development of speech, social skills and emotional expression. In a follow-up study 15 and 20 years later, W. Dennis showed that even those children who were subsequently adopted and found in favorable conditions showed a certain lag (associated with development) in reaching maturity. Those who were not fortunate enough to leave the orphanage, found a marked lag behind the social and age standards for the extension of life.

Professor A. M. Lobok and other authors who study individual myth-making in children and share his point of view, in fact, ignore the importance of direct and mediated communication between the child and his mother, adults and peers. This factor is auxiliary to them, secondary to the individual consciousness. Consequently, the secondary is the social motivation, orientation to the assessments of others.

On the contrary, it is well known to specialists in Child Psychology that the normal development of a child always occurs in conditions of communication with parents, adults and other children. This is a condition for the assimilation of cultural norms, the effective development of mental processes, in particular, thinking and speech (B. G. Ananyev, 1935; L. S. Vygotsky, 1956).

G. Kreig, analyzing the mechanisms of mental development of children, notes the determinative value of their social contacts with peers and adults. In particular, she writes: "The environment stimulating the development of the child is created by caring for it by adults ... the interpersonal relationships between children and those who bring them up have a decisive influence on the mental development of the first. During feeding, swaddling, bathing and dressing children, parents and others caring for them serve as a constant source of stimulation. Speaking and playing with children, they visually show them not only the relationship between the subjects, but also the relationships between people, encourage their achievements in mastering the language. Even the simplest actions, based on imitation, are included in the context of the complex social interaction between the child and the adult caring for him" [4, p. 286]. 


\section{Chapter 5. Psychological sciences}

\section{Self-expression in children as a phenomenon of self-advertisement}

The problem of self-expression in children is closely related to the phenomenon of self-promotion in adults. The factor of communication presupposes a sociocultural correction of the child's actions. The social curbing of his spontaneous natural biologically prescribed activity under normal conditions occurs immediately after birth, from the moment the mother chooses the position for feeding, from the act of swaddling, etc.

The fact that at first a modern child is "interested" in everything that surrounds him or her, regardless of his biological and social needs, is only a necessary condition for his/her further cultural adaptation. Nature seems to be preparing a child for birth in this or that historical epoch and at the same time cares about the mechanisms of adaptation and survival. The child can not "take an interest in everything" for a long time; he must sooner or later adapt to the conditions of life in which he is born, and choose the sphere of his interests, form an individual system of value orientations as the main maxim in the structure of the personality [8]. E. Fromm emphasizes that all orientations have their place in human life, and the domination of one or another depends to a greater extent on the peculiarities of the culture in which a person lives [8].

However, it is this plasticity that allows him to successfully adapt to the conditions of his habitat and turn into either a mythical "Mowgli" that reproduces the experience of communication with a wolf, or in "a reasonable person" who reproduces the experience of communicating with other people.

A well-known Russian specialist in the field of Child Psychology, Professor V.S. Mukhina (1985) writes that each age is distinguished by selective sensitivity to different types of education. There are age periods when learning has the greatest impact on a person's mental development. Such periods are called sensitive. From one and a half to three years is a sensible period which is well known for teaching a child speech. At this time, speech is learned especially easily and affects the behavior of the child and his mental processes - perception, thinking, emotions, etc. If, for some reason, a child under the age of three did not begin to speak, then the mastery of speech is difficult. So, in deaf-mute people, a lag in the development of mental processes is found (there is no story-role play, there is no ability for objective drawing, etc.). 


\section{Partyko Neonila, Savka Iryna}

The presence of sensitive developmental periods is explained by the fact that the greatest influence on the training is provided precisely by those psychic qualities that are just beginning to form. At this point, they are the most plastic, they can be sent in any direction. It is much more difficult to rebuild already established qualities.

Considering the ways of applying the system approach to the analysis of states of consciousness, Ch. Tart writes that as beings with a definite structure of the body and nervous system, people, generally speaking, can realize a very large number of possibilities for their behavior. But each of us is born in a particular culture, within which only a small part of these opportunities are selected and developed: some are rejected by culture, to others it remains indifferent. Only a small fraction of these possibilities, which have passed through the sieve of cultural selection, and besides overcoming a number of random obstacles, form the structural elements of which the ordinary consciousness of man is composed. We are both victims and pets of this cultural selection (Tart, 1994, p. 181).

Psychologist M. Ainsworth draws in this regard a special attention to such forms of behavior that ensure the closeness of the child to the person next to him. They include a signaling behavior (crying, a smile, voice signals, looks, movements), caused by the behavior of another person and active actions aimed at achieving physical contact (clambering, grasping and clasping, clinging). All these forms of behavior testify to attachment only if they are aimed at those people who care for the baby, and not for others in general.

Thus, by showing activity, the child strives to make people around him pay attention, praise, caress, stroke, etc. He is angry, fussy, shows disobedience if his demands are ignored. Already at the earliest stages of child development, the child's personality manifests itself, the orientation toward the assessment of others and the simultaneous desire to change the criteria and conditions for social interaction, the desire to declare itself, to stand out, to lead, to rule others is manifested.

Any adult person who has young children and who is inclined to observe them, knows cases of children's verbal creativity, when, in order to enjoy and like an adult, the child distorts words, replacing commonly used and understandable expressions with those unfamiliar to others, based on some very remote personal or absolutely random associations. At the same time, without understanding, he immediately abandons his 
creativity and seeks to be understood, especially if he can use the dialogue to achieve his goal.

A child can designate by sound or a combination of sounds a certain thing, but often does so in order to draw the attention of adults to it. Calling a thing with his own "word", he comes into contact with an adult, waits for approval of his actions, affectionate look, praise, smile, encouragement. He seems to speak to an adult: "Look, what an interesting thing, I remember that you showed it to me earlier. You see how good I am, I've remembered, praise me!". At the same time, pointing to a thing, the child tries to reproduce exactly those sounds that he heard from an adult, he imitates. His language - this is not some purely individual artificial mythological language, invented by him to close from contact with adults, to reject their culture of language, to create a barrier on the way to society, as follows from the statements of A. M. Lobok. His language is an attempt to reproduce the word noticed by adults, an initial form of establishing social contact. In this case, the word used by him can be absolutely unlike the word used by an adult, or remind him only in general terms. It's just that a child hears and so hears what he hears. He does not yet have a clear biological connection between the systems for processing auditory signals and reproduction.

The fact that a child becomes a person in the process of communication and self-expression, rather than unilateral influence of adults, for example, parents, is confirmed by many researches and observations of psychologists.

G. Kreig writes that infant babble is so attractive that adults around the world are delighted with it and are trying to imitate it. Apparently, in the process of babbling babies learn to pronounce the sounds of their native language, which in the future will come in handy when mastering articulate speech [2]. In this way, the sounds of the baby are a reaction to the speech he hears, even though he does not yet understand the meaning of words. Therefore, although the babbling is a form of communication and interaction with other people for babies, it is also cognitive activity, a kind of experimentation" [4, p. 277].

Thus by learning to label objects with sounds and wanting to enter into closer contact with adults, the child begins to think up words on his own. But behind this paralinguistic activity is again "the turn to another person". The child seems to be gaining material for the future communication.

L. Rubinstein wrote that the child does not ripen at first and then is educated and trained, but he matures, being educated and trained, that is, 


\section{Partyko Neonila, Savka Iryna}

under the guidance of adults, mastering the content of culture that created mankind; the child does not develop and is brought up, but develops, educated and trained, that is, the maturation and development of the child in the course of education and upbringing is not only manifested, but is also being accomplished. The organism develops by functioning; man - adult develops, working; a child develops, being educated and trained. This is the basic law of the child's mental development.

By creating a myth, a person, in particular a child, does not escape from reality, above all social. On the contrary, he declares about his existence, the desire to communicate, to be understood, to achieve respect, recognition. He wants to become closer, but at the same time to remain himself. However, from this contradictory state there is only one way out: socialization, correlation of individually constructed myth-words with public culture, gradual rejection of obscure myths, their transformation into understandable, for the sake of dialogue, for mutual understanding.

"The life of an infant depends entirely on the adult", writes Professor V. S. Mukhina. - The adult satisfies the organic needs of the child - feeds, bathes, turns him from one side to the other. Adult satisfies also the growing need for a variety of impressions: the baby is visibly enlivened when it is picked up. Moving in space thanks to an adult, the child has the opportunity to see more objects, see their displacement, touch them, and then grasp. The basic auditory and tactile impressions also come from the adult" [5, p. 59].

The author notes that already in the complex of animation, the positive emotional attitude of the child to an adult is revealed, a clear pleasure from communicating with him. By four or five months, communication with adults becomes selective. The kid begins to distinguish his own from others, the kid rejoices the familiar adult, a stranger can cause him fear.

And we asked ourselves what is self-expression in children and how it is motivated. Is the self-expression in young children their self-promotion and on whom is it directed? The psychologists also note that in the process of communication between a child and adults, each of them develops in a logical way, and this happens in close connection with such psychological variables as self-esteem, achievement motivation, self-expression, "self image" and the like. So, the studies show that two-thirds of self-assessments of two-three-year-olds are reduced to the saying: "I am the best!". Moreover, objective evidence and evidence for this in the possession of the child are most often absent, and such statements are only a means of self-affirmation. 
At the same time, self-expression is a self-advertisement of a child becoming an adult, gradually from an unjustified desire to separate himself by any means and attract the attention of others gradually turns into a desire to justify the expectations of only significant people and to master only those cultural norms that are of value to him.

Explaining this psychological mechanism from the point of view of analytical psychology A. Adler writes: "Like an adult, the child wants to surpass all his rivals" [6].

Our observation of three-year-old children showed that their self-expression helps to advertise themselves and thus attract the attention of meaningful adults to children's self-affirmation. Children's self-affirmation, in turn, helps to grow up children of an early age.

Based on the results of our conversations with the parents of these threeyear-old children, this phenomenon has been confirmed in children of an early age.

\section{Conclusions}

All life, every day, each of us, wishing to please the people around us, constantly engaged in advertising activities, in particular self-promotion. Responding well about the relatives and friends in a society, we also do advertising for them. As a result, a complex system of social connections and relations of a huge number of people with each other arises in society, the psychological characteristics of which have not yet been studied in sufficient detail by science.

Self-advertising is one of the most common and most ancient types of advertising activities. Just like traditional commercial advertising, it solves three problems. Engaged in self-promotion, a person seeks: 1) to stand out among those people whom he values as equal to himself in the conditions of competition; 2) to present oneself as a person equal in status to those who have achieved any significant success and, possibly, even the legislator of a certain mode (social norms of behavior); 3 ) demonstrate yourself in the most favorable light, create a decent image, like others. In the first case, a person demonstrates unusual behavior; in the second - full correspondence to the established standards of behavior, norms, provided that they are significant for him; in the third - he tries to work on his own image, regardless of the presence of competition. In any case, the basis of human behavior is the same psychological mechanisms and, in fact, the same motivation. It is 


\section{Partyko Neonila, Savka Iryna}

this multi-aspect of self-advertising that often reveals systemic contradictions in the study of this phenomenon.

It should be noted that neither the theory of the "mirror I" by Ch. Kh. Cooley, nor the theory of "symbolic interactionism" of J. Meade, nor the theory of social instruction of A. Bandura, nor any other similar theories explain the sources of individuality of a person, the originality of his thinking and behavior, dissimilarity to other people. All of them are based on the notion that a person reproduces, in one way or another, preconceived patterns of behavior and thinking that have already been formed before him.

The motivation for self-expression and self-promotion, according to several authors, is exacerbated in adolescence. First of all, young, but gradually maturing people "solve" the psychological problem of raising their social status. They do not need to attract attention and publicly demonstrate their successes, originality, individuality and independence, as growing up and personal advancement involves overcoming the strongest factor the psychological pressure of adults involuntarily degrading the dignity of young people and holding back their ambitions and initiative.

And we asked ourselves what is self-expression in children and how it is motivated. Is the self-expression in young children their self-advertisement and on whom is it directed? The psychologists note that in the process of communication between a child and adults, each of them develops in a logical way, and this happens in close connection with such psychological variables as self-esteem, achievement motivation, self-expression, "self image" and the like. So, the studies show that two-thirds of self-assessments of two-three-year-olds are reduced to the saying: "I am the best!". Moreover, objective evidence and evidence for this in the possession of the child are most often absent, and such statements are only a means of self-affirmation.

At the same time, self-expression is a self-advertisement of a child becoming an adult, gradually from an unjustified desire to separate himself by any means and attract the attention of others gradually turns into a desire to justify the expectations of only significant people and to master only those cultural norms that are of value to him.

Explaining this psychological mechanism from the point of view of analytical psychology A. Adler wrote that like an adult, the child wants to surpass all his rivals.

Our observation of three-year-old children showed that their self-expression helps to advertise themselves and thus attract the attention of meaning- 
ful adults to children's self-affirmation. Children's self-affirmation, in turn, helps to grow up children of an early age.

Based on the results of our conversations with the parents of these threeyear-old children, this phenomenon has been confirmed in children of an early age.

Some people, wishing to stand out and possessing a developed ambition or vanity, are absolutely not sensitive to any objective evidence of the huge role of self-promotion in their life. Psychologically defending, people often appeal to spiritual substances, explaining their actions and deeds of other people, or disinterested desire for knowledge, or ethics or a kind of "higher meaning", for example, the service of ideals, the observance of divine commandments, considering ambition and vanity as one of the most terrible mortal sins for which a person can never receive forgiveness.

\section{References:}

1. Ananyev B. G. (1996). Psykhologia y problemy chelovekoznaniya: Izbrannyye psykholohicheskiye trudy. [Psychology and problems of human knowledge: The selected psychological works]. Academy of Pedagogical and Social Sciences, Moscow Psychological and Social Institute: [ed. by A. A. Bodaliov]. (in Russian)

2. Voloshyna N. V. (2013). Vikova Psykhologia. [Age psychology: A summary of lectures (module I)]. Zaporizhzhya: ZNTU. (in Ukrainian)

3. Vygotsky L. S. (1992). Ranniy vozrast. [Early age]. (in Russian)

4. Kreig G. (2005). Psykhologia razvitiya [Psychology of Development] St. Petersburg: Peter, 2005. (in Russian)

5. Mukhina V. S. (2005). Vikova Psykhologia: phenomenologia razvitiya [Age psychology: phenomenology of development]. (in Russian)

6. Adler A. (1927). The practice and theory of individual psychology]. New York: Harcourt, Brace \& World, 1927.

7. Voloshyna N. V. (2018). Value orientations in the structure of the personality. Development trends in pedagogical and psychological sciences: the experience of countries of Eastern Europe and prospects of Ukraine: monograph. Riga, Latvia: "Baltija Publishing", 2018, pp. 158-176. 